\title{
Has a Mother's Role been Substituted? A Study of Mother's Empathy toward their Young Children in Jakarta
}

\author{
Dr. Charyna Ayu Rizkyanti \\ Faculty of PsychologyUniversity of Pancasila \\ Jakarta Indonesia \\ Dr. Ade Iva Murty \\ Faculty of PsychologyUniversity of Pancasila \\ Jakarta Indonesia \\ Citra Wahyuni, M.Si \\ Faculty of PsychologyUniversity of Pancasila \\ Jakarta Indonesia
}

\begin{abstract}
Regardless of woman status (whether a housewife or a career woman), the number of mothers who need to employ nannies are increased, particularly in Jakarta. In consequence, the mother's empathy is needed to detect each changes that could potentially harm children's physical and psychological healthiness relationship due to different caregivers explain this sentence. The current research aims to investigate mother's empathy toward their young children in Jakarta, Indonesia. A total of 250 mothers who have children under the age of seven completed the empathy scale that was adapted from The Basic Empathy Scale (BES) by Jolliffe and Farrington (2006). There were 88 mothers with nannies and 159 mothers without nannies participated in this research. All mothers were divided into three categories of working status, i.e fulltime mothers $(60 \%)$, full-time working mothers $(32.8 \%)$ and part-time working mothers $(6.8 \%)$. The result revealed that there is significant difference of affective empathy between mothers who have nannies compared to mothers with no nannies. Mothers without nannies were found having higher affective empathy than mothers with nannies. In addition, there is also a difference of cognitive empathy between full time mothers and working mothers where full time mothers show higher mean score than working mothers. This finding implies the significancy of attachment between mothers and children relationship in the interest of developing mothers' empathy. Through attachment, mothers with nannies might elevate their skill to emphatize both cognitively and affectively, thus, mothers could identify and understand their children's need more accurately.
\end{abstract}

Keywords: mothers, empathy, affective-cognitive empathy, nannies

\section{INTRODUCTION}

Children violence can occur in many forms, such as sexual, physical, psychological or a combination of any of these. The Global Report 2017: Ending Violence in Childhood stated that 73.7 percent of Indonesian children aged 1-14 years experience violence at home ${ }^{12}$. The Indonesian Child Protection Commission (KPAI) has recorded that there are 4.294 cases of child abuse committed by families and caregivers. It becomes a huge concern while KPAI has also pointed that $75 \%$ of children in Indonesia are cared for by another caregivers which might come from people in extended families or official babysitter. A previous research about child abuse had found that $16.67 \%$ of sexual abuse is perpetrated by babysitters ${ }^{23}$. In other words, there are many potentially unexpected events could happen when the mother is not around 38 . 
A caregiver or nanny previously has to take care of children at home in their parents' absence. Notwithstanding, nowadays family's paradigm has been shifted in terms of taking care of children. The presence of nanny is not only needed by family with working parents (especially working mothers), but also full time mothers often do hiring nannies to take care of their children. Data from the All Indonesian Workers Training Association (APPSI, 2015) shows the increasing trend of Indonesia's middle class has triggered high demand for domestic workers, including the demand for hiring nanny ${ }^{2}$.

It is important to explore the extent of mothers' ability to detect their children's changes, regardless of mothers with or without nannies. By early detection, mothers can protect their children from harm situation. As Erikson's theory stated, start form the first year of life, the mother's main duty is about to strive in understanding of how their baby feels. This effort would be difficult to achieve when mothers' duty used to be done by other caregiver, such as babysitter or even family member. Moreover, the mother's ability to sensitively interpret and respond to her child's cues is the key of positive attachment which underlie the development of healthy relationships ${ }^{1}$. The way parents sensitively response to children's distress might impact children's healthy social and emotional development.

The ability to understand and feel the way others' thinking and feeling is called empathy (Baron-Cohen et al., 2004), which is also a central component of positive parenting practices ${ }^{9}$. Mothers with empathy are better in reading children's emotional cues, thus, it could lead mothers to detect and respond to their children's need accurately. Children whose parents were unresponsive to their needs would tend to deactivate their attachment system in order to repress their emotions and withdraw from intimate relationships as adults ${ }^{25}$. Conversely, the empathic parents might develop children's self-regulation skills ${ }^{23}$.

Considering that a father's role is commonly as the main breadwinner, the mother is expected to be involved more in childrearing. This situation is changing due to the increasing of female employment, either full time or part time. Although it is well noticed due to the importance of the parents' presence and also of their competence in accomplishing the parental roles, still, many families in various situations often resort to the servicees of a nanny ${ }^{13}$. In consequence, the need of someone to take care of the children at home is increased. However, employing an external caregiver needs a lot of consideration since there are some family's values and beliefs are embedded in childrearing. One study by Greenfield, Flores, Davis and Salimkhan (2008) ${ }^{14}$ investigated the possibility-based differences in caregiving beliefs between nannies and the parents who employ them. The results found a number of nannies-mothers differences in terms of childrearing approaches around bedtime and sleeping routines, mother's role in balancing work and family, how adults should talk to children, etc. In sum, instead of physiological needed, there are psychological things would be experienced in terms of transferring family values and beliefs. This may explain why parent's empathy, particularly mother, is needed in order to detect each changes that might be unsuitable with family values or beliefs.

However, among many research that investigated about nanny and working mother relationship, none have focused on mothers' empathy in an effort to understand the nature of the childrearing, with live-in nannies. Based on the explanation above, it is important to investigate mothers' empathy toward their young children, particularly for mothers who employ nannies due to another caregiver is now in charge of taking care of the children at home. By empathy, mothers will be able to understand the intentions and predict their nannie's behaviour toward the children, also will lead to accurately recognize and understand their children's emotional state ${ }^{15}$. Mothers will be able to get to know easily if unusual things 
happened though they are not around. Mothers who have empathy could read nonverbal cues because they are used to acknowledge what is causing their children's emotion. Therefore, the main aim of this research is to describe mothers' empathy (with or without nannies) toward their young children. In addition, this study also examined the effect of mother status (full-time mothers, full-time working mothers and part-time working mothers) that might affect mothers' empathy.

\section{LITERATURE REVIEW}

The word of empathy in English was invented by Titchener that derived from the translation 'Einfuhlung', hence, Lipps defined it as the tendency of perceivers to project themselves into the objects of perception (in Hakansson, 2003) ${ }^{16}$. Therefore, the emergence of empathy is considered vital in contributing to moral emotion, motivation, behavior and also cognition ${ }^{18}$.

Particularly, developmental psychology interested of how empathy can be fostered in early childhood. The emergence of empathy showed up in the first year of life and yet continue to mature in older children and adults. Hoffman (2000) ${ }^{17}$ who explained five stages of empathy that might develop gradually in order to feeling other's distress, i.e.,

a. Global empathy. This reactive newborn cry shows while an infant cannot yet differentiate himself from the other. The infant appears cries in response to others' crying. This sort of crying is not simply imitating, but it shows the infant responds to a cue of others' distress as what is happening to them.

b. The egocentric empathy. The empathy gradually moves in to difference reaction in toddler stage. Children now can respond to another's distress as though they themselves were in distress, but still lack a clear distinction between self and other. They actively offer help, but the kind of help is what they themselves would find comforting and it is in that sense egocentric. Children show their effort to connect another person's discomfort with their own. When children saw her mother crying, they were giving something to make her mother feels better. However, it is unclear whether children understand what her mother feeling.

c. Quasi-egocentric empathy distress. At this stage, children realize the distress is the other's, not their own. Children become aware that other people's feelings can differ from their own, but they confuse the other's inner states with their own and try to help by doing for the other what would comfort themselves.

d. Veridical empathic distress. Children come closer to feeling what the other is actually feeling because they now realize that the other has inner states independent of their own. Their responses to distress may become more appropriate to the other person's needs. Thus, children at this age become more helpful and caring to others.

e. Empathy for another's life condition. Now children can emphatize for another's experience beyond the immediate situation. Children become aware that others' feelings may not just be due to the immediate situation but also be found with respect to entire groups of people (the poor, the oppresses, etc) and thus transcend immediate experience.

The child starts learning about other's distress over the closest ones, generally from his parent. Particularly in mother-child relationship, the presence of secure atachment since the very beginning leads the mother to recognize and respond to their child's needs, thus, mothers should have the capacity to see things from their child's perspective ${ }^{26}$. By this relationship, mother and child are together learning about each other thoughts and feeling untill they are emotionally attuned. When the mother is being in empathy status, means, she can absorb the child's thought and yet, she is in the same emotion as the child. Therefore, attachment security provides a solid foundation for empathy ${ }^{34}$. 
Empathy is simply defined as the understanding and sharing in another's emotional state or context $^{6}$. By its definition, empathy often falls into multidimensional perspective which consists of two components, affective and cognitive ${ }^{3,17,19}$. The affective component emphasizes empathy as an observer's emotional response to the affective state of another ${ }^{3}$, while cognitive empathy is defined as the conscious understanding of another's emotion by taking their perspective ${ }^{7,33}$. In detail, Davis $(1980)^{7}$ divided affective and cognitive empathy into two subscales, respectively. Affective empathy contains of empatuc concern and personal distress scales, while cognitive empathy contains of fantasy anf perspective-taking scales.

Previous research from Quinn (1991) ${ }^{29}$ showed there was relationship between parental empathy and attachment, where further research by Zimmerman \& McK.Doan (2008) ${ }^{38}$ had also found that there was a relationship between empathy and prenatal attachment. Since the baby was born, they will feel the attachment to the familiar figure they see and feel at the moment they need it ${ }^{35}$. This attachment can not run instantly, but must be built through a process. Nevertheless, it was explained that why some people by nature are more empathic than others, thus the ability to empathize may vary in individual ${ }^{36}$. By those researches, parental empathy was found to contribute to better children in having empathy, and further, a better children profile, both psychologically such as developing children emotional regulation ${ }^{10}$ and physiologically ${ }^{25}$.

Parents who could detect change in their children's behavior are those who actively involved in their children's lives and emotionally available. Parents with high empathy might be more accurate in their assessment of their children's abilities and skilled at anticipating their needs. This may allow parents to be more sensitively facilitate the development of children's selfregulation by giving support ${ }^{11}$.

\section{Research Objective}

The objective of this study was to investigate mothers' empathy toward their young children in Jakarta, Indonesia.

\section{RESEARCH METHODOLOGY}

This research was conducted by descriptive quantitative approach. Data was taken from 250 mothers who have children under the age of 7 in Jakarta city-Indonesia. The reason why this research took mothers with children under the age of 7 due to obtaining children's answer to specific questions at this age is often limited and incomplete. Since the limitation of their language, knowledge, etc, children are prone to experience either abuse or violence that is naturally often does not involve eyewitness other then perpetrator and the victim ${ }^{5}$. Therefore, mothers' ability to detect and identify nonverbal cues is needed, moreover for mothers who can not fully take care of the children since they must work. The participants has been selected from a number of children day care/kindergarten centers in Jakarta. There were 88 mothers with nannies and 159 mothers without nannies participated in this research. All mothers were divided into three categories of working status, i.e full-time mothers (62\%), full-time working mothers $(32.8 \%)$ and part-time working mothers (6.8\%). We used these three categories based on the increasing of female employment and the need of employ an external caregiver are also getting higher.

Probability sampling - cluster sampling has been conducted in five areas which is representation of Jakarta City, i.e, Central Jakarta, South Jakarta, West Jakarta, North Jakarta and East Jakarta. This study used a quantitative method with non-experimental design. There were 250 out of 300 questionnaires which were used for further analysis. 


\section{Measurement of variables}

The mothers' empathy measurement was adapted from the Basic Empathy Scale (BES) by Jolliffe and Farrington (2006) ${ }^{20}$. It consists of 20 items which are used to determine the level of mothers' empathy based on two components; affective and cognitive with focus on four basic emotions (anger, fear, happiness and sadness).

There are nine items which measure cognitive empathy and eleven items measure affective empathy. The participants have to give their ratings on a 4-point Likert type scale $(1=$ Strongly Disagree, 2 = Disagree, 3 = Agree, $4=$ Strongly Agree). The scale was tested for its validity by using confirmatory factor analysis (CFA) in order to evaluate each dimension of empathy, cognitive and affective dimension.

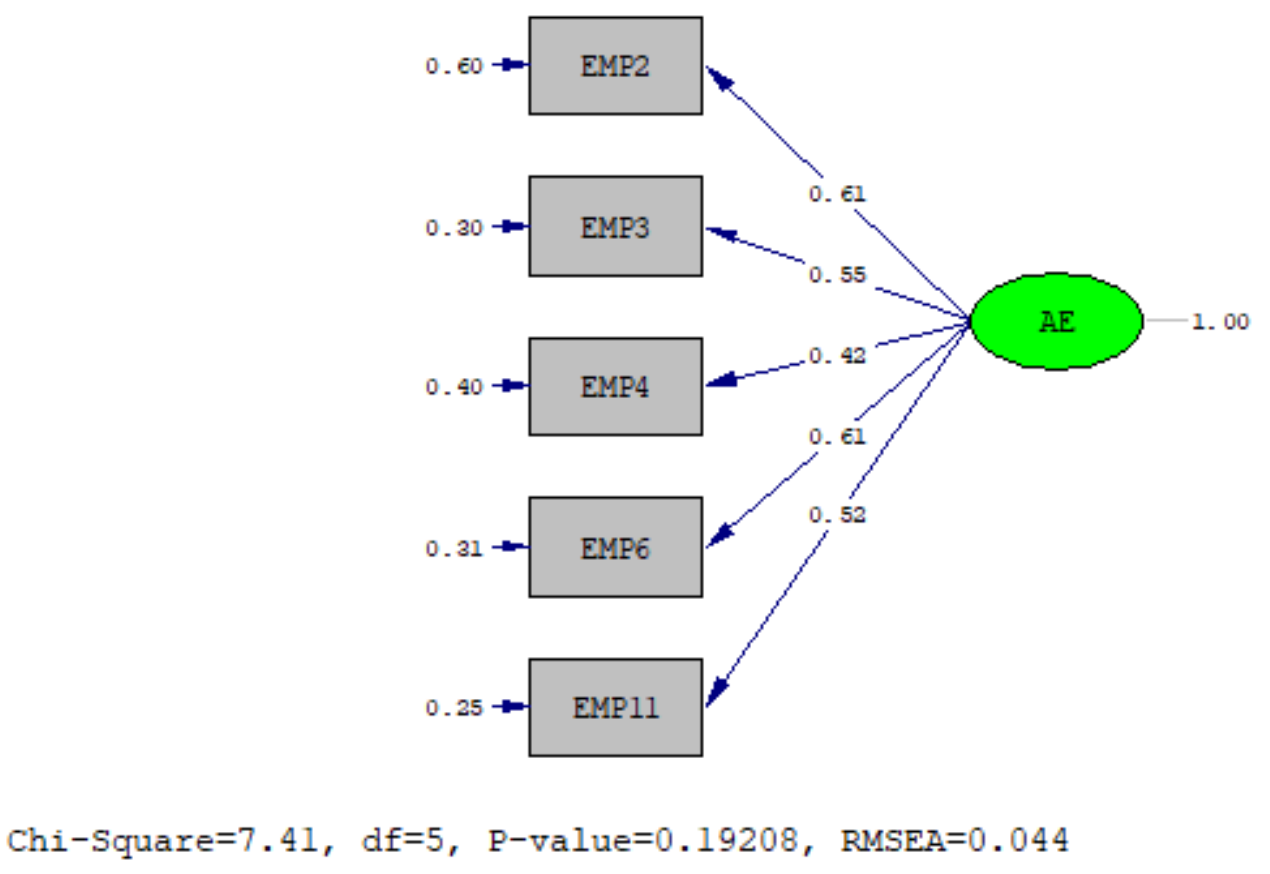

Figure 1. CFA model for affective empathy

There are only 5 valid items out of 11 items in affective empathy with the value of factor loading for affective empathy items were ranging from $.42-.61$ by estimated reliability (ER) $=.797$. It was also showing a good fit of the data, as the value of RMSEA $=.044$, GFI $=.99\left(\chi^{2}=\right.$ $7.41, d f=5, p=0.19208)$. 


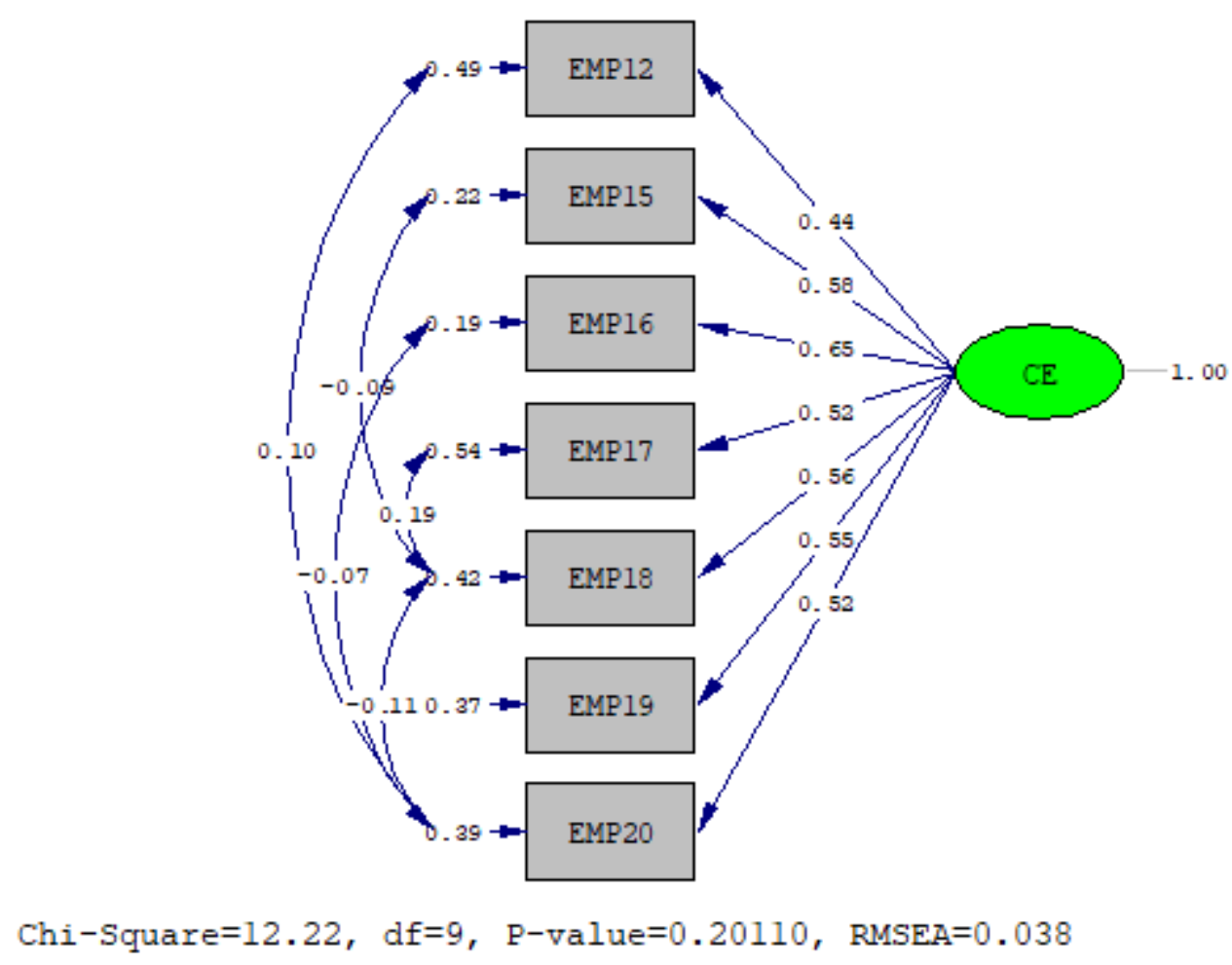

Figure 2. CFA analysis for cognitive empathy

In cognitive empathy, it was found 8 valid items out of 9 items with the value of factor loading were ranging from $.044-.65$ with estimated reliability $(E R)=.846$. It was also showing a good fit of the data, as the value of RMSEA $=.038, \mathrm{GFI}=.99\left(\chi^{2}=12.22, d f=9, p=0.20110\right)$.

\section{RESEARCH FINDINGS AND DISCUSSIONS}

In this section, the results of the study will be explained, and it will consist of descriptive statistics of each dimensions of mothers' empathy (with and without nanny), and also examine the difference of mothers' empathy based on three working status.

Table 1. Mann-Whitney test for Mothers' cognitive-affective empathy for with or without nannies

\begin{tabular}{lccc} 
& With Nannies $(M)$ & Without Nannies $(M)$ & $p$ \\
\hline Cognitive Empathy & 112.97 & 129.58 & 0.083 \\
Affective Empathy & 110.05 & 131.06 & 0.028 \\
\hline
\end{tabular}

Using Mann-Whitney test, it was found that affective empathy did show a difference between mothers with and without nannies while cognitive empathy did not show any difference. By mean of affective empathy, it shows that mothers without nannies $(M=131.06)$ were higher than mothers with nannies $(M=110.05)$.

Table 2. Kruskal-Wallis Test of Cognitive-Affective Empathy Based on Mothers' Working Status

\begin{tabular}{lllll}
\hline & $\begin{array}{l}\text { Full-time } \\
\text { mothers }(M)\end{array}$ & $\begin{array}{l}\text { Full-time } \\
\text { working } \\
\text { mothers }(M)\end{array}$ & $\begin{array}{l}\text { Part-time } \\
\text { working } \\
\text { mothers }(M)\end{array}$ & $p$ \\
\hline $\begin{array}{l}\text { Cognitive Empathy } \\
\text { Affective Empathy }\end{array}$ & 137.77 & 106.17 & 103.12 & 0.002 \\
\hline
\end{tabular}


Further analysis revealed that there was a difference for cognitive empathy between those three mother status, i.e., full-time mothers, full-time working mothers and part-time working mothers. It was found that full-time mothers have the highest mean score $(M=137.77)$ among the other two, which then followed by full-time working mothers $(M=19.8171)$ and the last was part-time working mothers $(\mathrm{M}=19.4118)$.

The present study aims to investigate mothers' empathy toward their young children and hope that we could learn more concerning empathy in the mother-children-nanny relationship.This research found there is a difference of affective empathy between mothers who have nannies and no nannies. By this result, it is revealed that mothers who take care of their children by her self were found having more affective empathy than mothers who take care of their children with nannies. Mothers without nannies showed a better skill in sharing emotions with their children than other mothers, in which they become aware of each emotion changes as a sense of caring for their children

Mothers with an affective empathy have such an appropriate emotion that triggered by another's emotion, particularly their children. When the affective empathy activated, mothers are able to empathize and experience their children's concern and personal distress, such as anxiety and discomfort in interpersonal situations ${ }^{7}$. Some researchers believe that affective empathy is primarily process of emotional contagion ${ }^{26}$, and also can feel their children emotion with an appropriate emotion ${ }^{3}$. Mothers without nannies are more able to share their feeling (fear, sadness, anger, happiness) since they might face all their children's needed and problems day by day.

Full time mothers were also found having higher cognitive empathy compare with working mothers (full-part time working mothers). This result shows the new point of view regarded full time mothers spend more time at home but their empathy are better in terms of cognitive than working mothers. It explains how full-time mothers succeeded to develop their cognitive empathy by applying their intuitive perspective taking as well as intentionally projecting to detect how her child is feeling ${ }^{30}$. Mothers with higher cognitive empathy show how they are having awareness and understanding of their children internal states, such as thoughts, perceptions, intentions, especially feelings.

Parents who are better able to empathize with their children provide more attuned caregiving 9 . Specifically, the relationship between children and mother is the most important moment in a child's life especially during early childhood ${ }^{28}$. Empathy is a central key to make bonding between mothers and young children, particularly for pre-verbal infant. Empathy allows mothers to easily interact toward their young children as they can imagine and feel the emotions of them. Mothers with no nannies must have huge effort not only to take care of children physically but also psychologically, particularly mothers who have infants. However, it causes some positive impacts such as the stronger attachment bond of each other. Bowlby explained further that attachment to a caregiver over the first year of life has important consequences throughout the life span ${ }^{31}$. When attachment becomes stronger between mother and the child, the emotional connection will be also escalated. Mothers might detect each changes toward their children due to the ability to empathize is becoming enganged, both cognitive and affective.

It is considered that parents, especially mothers must have more time to interact with children since their role as a caregiver. Regardless of mothers' status, building emotional availability through habitual moments might create mothers-children quality time relationship. Due to the condition of working mothers at office which made they chance to interact with children lessen, 
they must have a strategy to gain sensitivity to the environment through various everyday situation. Taking into account of having more time to care of the children leads full-time mothers might pay attention to their child's signals and judging the motives behind the signals ${ }^{21}$. By building a daily practice with children, it will enhance mothers' sensitivity to children's feeling, thus, mothers might respond to overt cues of children's emotional state.

Specifically, maternal empathy appears to enhance the quality of friendship while the children has grown up. Full-time mothers who raise children by themselves are capable to respond overt cues (e.g., facial expression, voice quality, etc) which allows them to experience cognitive empathy, yet, lead the quality of children's social functioning32. Furthermore, their ability to effortfully infer children's intention lead to their capability to analyse the problems with a strong strategy.

\section{SUMMARY AND CONCLUSIONS}

This study revealed that mothers who take care of their children by themselves were found having more affective empathy than mothers who take care of their children with nannies. Further analysis also revealed that full-time mothers have a better cognitive empathy than fulltime working mothers as well as part-time working mothers.

Empathy becomes the key in parenting practices in order to make the child a healthy, emotionally, happily and responsibly in their future. Regardless of parent's status (e.g., working, marriage, employing nanny, etc), mothers' empathy (cognitive and affective) must be continuously strived to develop. Mothers with affective empathy will be easily to get the emotional state transferred over their children, while mothers with cognitive empathy could focus their attention, read expressive signals as well as situational context cues and try to understand the current situation that might happen to their children.

This study also contributes to the general understanding of the importance in having empathy as the key of parenting practices, particularly for mothers. It is strongly related with mothers' reaction into the emotions of their children, yet determine of how children will interact in their relationships later on in future. By having empathy, mothers could interpret a child's cues and be more sensitive to a child's need, and hence, lead to the child health emotionally and responsibly in their future. Therefore, an understanding of who our children will become an investation when parents are confronted with difficulties that must be faced throughout the life span. It might explain of why many theories still stand for unchangeably statement about the noteworthy of mother as main caregiver.

\section{RECOMMENDATION}

This research is a preliminary study about mothers' empathy in Jakarta. Despite all of limitations such as unbalancing of the research areas and the number of mothers with or without nannies, the current study reinforces the importance of having affective and cognitive empathy in parenting practice, particularly for mothers who employ nannies and also working mothers. From methodology perspective, further research might divide the participants in to 4 categories, i.e working mother with nanny, full-time mother with nanny, working mother without nanny, full-time mother without nanny. Hence, future research would be better to examine the importance of intervention in developing mother's empathy, particularly for mothers who employ nannies and working mothers.

Mothers' empathy should be taught as a skill and must be developed with practice until they can reinforce images that they are competent and feel good about them selves to raise children. Behavioural checklist can be used to improve the reliability and specificity of measures in 
composing routine activity, such as spending time together to read a book with their children before sleep, having dinner together in weekend, etc. These habituations will become such a trigger for the development of mothers' empathy.

\section{References}

Ainsworth, M. D. S. (1985) Patterns of mother-infant attachment: Antecedents and effects on development. Bulletin of New York Academy of Medicine, 61, 771-790.

APPSI (2015, January 20). Kelas menengah tambah banyak, permintaan PRT makin tinggi. https://finance.detik.com/berita-ekonomi-bisnis/2807936/kelas-menengah-tambah-banyak-permintaan-jasaprt-makin-tinggi

Baron-Cohen, S. \& Wheelwright, S. (2004). The empathy quotient: an investigation of adults with asperger syndrome or high functioning autism, and normal sex differences. Journal of Autism and Developmental Disorder, 34(2), 163-175.

Borba. M. (2002). Building moral intelligence. San Fransisco: A Wiley Imprint.

Bruck, M., Melnyk, L., \& Ceci, S. J. (2000). Draw it again Sam: The effect of drawing on children's suggestibility and source monitoring ability. Journal of Experimental Child Psychology, 77, 169-196.

Cohen, D., \& Strayer, J. (1996). Empathy in conduct-disordered and comparison youth. Developmental Psychology, $32,988-998$.

Davis, H. M. (1980). A multidimensional approach to individual differences in empathy. JSAS Catalog of Selected Documents in Psychology, 10, 2-19.

Davis, H. M. (1983). The effects of dispositional empathy on emotional reactions and helping: A multidimensional approach. Journal of Personality, 51, 167-184.

Dix, T. (1992). Parenting on behalf of the child: Empathic goals in the regulation of responsive parenting. In I. E. Sigel, A. V. McGillicuddy- DeLisi, \& J. J. Goodnow (Eds.), Parental belief systems: The psychological consequences for children (2nd ed., pp. 319 -346). Hillsdale, NJ: Erlbaum Publishers

Field, T. (1994). The effects of mother's physical and emotional unavailability on emotion regulation. Monographs of the Society for Research in Child Development, 59. 208-227.

Fox, N. A., \& Calkins, S. D. (2003). The development of self-control of emotion: Intrinsic and extrinsic influences. Motivation and Emotion, 27, 7-27.

Gerintya, S. (2017, November 21). 73.7 Persen anak Indonesia mengalami kekerasan di rumahnya sendiri. Dilansir dari https://tirto.id/737-persen-anak-indonesia-mengalami-kekerasan-di-rumahnya-sendiri-cAnG.

Glevaanu, S. M., \& Gherghinescu, R. (2014). Nannies' abilities to relate woth the child as predictors for professional performance. Procedia - Social and Behavioral Sciences 127, 26-30.

Greenfield, P. M., Flores, A., Davis, H. and Salimkhan, G. (2008). What happens when parents and nannies come from different cultures? Comparing the caregiving belief systems of nannies and their employers. Journal of Applied Developmental Psychology, 29, 4, 326-336.

Gupta, A. M. (2015). Mothers' cognitive empathy towards their biracial children. Thesis. Claremont Colleges. (scholarship.claremont.edu).

Hakansson, J. (2003). Exploring the phenomenon of empathy. Doctoral Dissertation. Stockholm University. Sweden: National Museum, Stockholm.

Hoffman, M. L. (2000). Empathy and moral development: Implications for caring and justice. New York: Cambridge University Press.

Hoffman, M.L. (2000). The measurement of empathy. In C. E. Izard (Ed.), Measuring emotions in infants and children (pp. 279-296). Cambridge, UK: Cambridge University Press.

Jolliffe, D. ,\& Farrington, D.P. (2004). Empathy and offending: A systematic review and meta-analysis. Aggression and Violent Behavior, 9, 441-476.

Jolliffe, D. ,\& Farrington, D.P. (2006). Development and validation of the Basic Empathy Scale. Journal of Adolescence, 29, 589-611.

Kilpatrick, K. L. (2006). Parental empathy and child maltreatment. Research to Practice Notes. 
Manczak, E. M., Chen, E., \& DeLongs, A. (2015). Does empathy have a cost? Diverging psychological and physiological effects within families. Health Psychology. http://dx.doi.org/10.1037/ hea0000281.

Martin, J. E., \& Kourany, R. F. C. (1980). Child abuse by adolescent babysitters. Child Abuse and Neglect, 4, 15-22.

Mikulincer, M., Shaver, P. R., \& Pereg, D. (2003). Attachment theory and affect regulation: The dynamic development and cognitive consequences of attach- ment-related strategies. Motivation and Emotion, 27, 77-102.

Miller, G. E., \& Chen, E. (2010). Harsh family climate in early life presages the emergence of a proinflammatory phenotype in adolescence. Psychological Science, 21, 848-856.

Nummenmaa, L. Hirvonen, J., Parkkola, R., \& Hietanen, J. K. (2008). Is emotional contagiom special? An fMRI study on neural systems for affective and cognitive empathy. NeuroImage, 43, 571-580.

Oppenheim, D., Koren-Karie, N., \& Sagi, A. (2001). Mothers' empathic understanding of their preschoolers' internal experience: Relations with early attachment. International Journal of Behavioral Development, 25(1), 16-26.

Perry, B. D. (2001). Bonding and attachment in maltreated children. The ChildTrauma Academy. www.ChildTrauma.org.

Quinn, M.M. (1991). Attachment between mothers and their down syndrome infants. Western Journal of Nursing Research, 13, 382-396.

Reniers, R. L. E. P., Corcoran, R., Drake, R., Shryane, N. M., \& Völlm, B. A. (2011). The QCAE: A questionnaire of cognitive and affective empathy. Journal of Personality Assessment, 93(1), 84-95.

Santrock, J.W. (2011). Life-Span Development. McGraw Hill.

Soenens, B., Duriez, B., Vansteenkiste, M., \& Gossens, L. (2007). The intergenerational transmission of empathyrelated responding in adolescence: The role of maternal support. Personality and Social Psychology Bulletin, 33, 2990311.

Stern, J., Borelli, J., \& Smiley, P. (2015). Assessing parental empathy: A role for empathy in child attachment. Attachment \& Human Development, 17(1), 1-22.

Troyer, D., \& Greitmeyer, T. (2018). The impact of attachment orientations on empathy in adults: Considering the mediating role of emotion regulation strategies and negative affectivity. Personal and Individual Differences, 122, 198-205.

Weiss, L. (2003). How to read your child like a book. Batam: Interaksara.

Yu J, Kirk M. (2008). Measuring of empathy in nursing research: a systematic review. Journal of Advanced Nursing, 64(5):440-454.

Yusuf, Y. (2017, March 17). Komnas PA: Jakarta masih rawan kasus kekerasan anak. Dilansir dari https://metro.sindonews.com/read/1189059/171/komnas-pa-jakarta-masih-rawan-kasus-kekerasan-anak1489675371

Zimerman, A., \& McK.Doan, H. (2007). Empathy: It's relationship to prenatal attachment and previous parenting experience. International Journal Prenatal and Perinatal and Medicine, 1(2), 29-41. 